\title{
PENGARUH PEMBELAJARAN JARAK JAUH DENGAN APLIKASI GOOGLE CLASSROOM TERHADAP EFEKTIVITAS BELAJAR BAGI SISWA PADA MATA PELAJARAN PENDIDIKAN AGAMA ISLAM SELAMA PANDEMI COVID-19 DI SMPN 1 PALIMANAN
}

\author{
Abdul Farhan, Nurlela, Iwan \\ Jurusan Pendidikan Agama Islam,IAIN Syekh Nurjati Cirebon, Indonesia \\ e-mail : abd.farhan@mail.syekhnurjati.ac.id,nurlela@mail.syekhnurjati.ac.id \\ iwan@syekhnurjati.ac.id
}

\begin{abstract}
The background of this research is the impact of covid-19, especially in the education sector, in this case education experiences a learning cycle that changes from the offline method (outside the network) or learning carried out in the classroom to an online method (in a network) or distance learning. far. Distance learning is an alternative that educational institutions need to do to keep the learning process going during the Covid-19 outbreak. One of the media that can be used in the distance learning process is the Google Classroom application.

The formulation of the problem in this research are: (1) How is Distance Learning (PJJ) using the Google Classroom application on PAI subjects at SMPN 1 Palimanan?, (2) How is the effectiveness of learning for PAI subject students during the covid-19 pandemic at SMPN 1 Palimanan?, (3) How much influence does the application of Distance Learning (PJJ) in PAI subjects using the Google Classroom application have on the effectiveness of learning for students at SMPN 1 Palimanan?.

To obtain the results of this study, researchers used quantitative research methods. The data collection techniques used in this study are: Questionnaires, interviews, and documentation. The data obtained were analyzed by performing variable tests and correlation tests.

Based on the problems above and after being analyzed, it can be concluded that: (1) In Distance Learning with the Google Classroom Application on PAI Subjects During the Covid-19 Pandemic at SMPN 1 Palimanan, it is included in the good category. Due to the recapitulation of the results of the questionnaire calculation, the results obtained are $85.5 \%$. (2) The effectiveness of student learning at SMPN 1 Palimanan is in the good category because based on the recapitulation of the results of the questionnaire on the effectiveness of learning, the results are $79.7 \%$ which indicates a good category. (3) There is a significant and positive relationship between distance learning and the google classroom application on the effectiveness of student learning, because $r$ is positive. This is evidenced by the correlation calculation using the product moment correlation hypothesis test and the correlation coefficient $r$ value is 0.650 which indicates a significant correlation.
\end{abstract}

Keywords: learning effectiveness, google classroom, distance learning.

\begin{abstract}
ABSTRAK
Latar belakang penelitian ini adalah dampak dari covid-19 khususnya dalam sektor pendidikan, dalam hal ini pendidikan mengalami siklus pembelajaran yang berubah dari metode luring ( luar jaringan) atau pembelajaran yang dilakukan di kelas menjadi metode daring (dalam jaringan) atau pembelajaran yang dilakukan dengan
\end{abstract}


jarak jauh. Pembelajaran jarak jauh merupakan suatu alternatif yang perlu dilakukan oleh lembaga pendidikan untuk tetap menjalankan berlangsungnya proses kegiatan pembelajaran selama wabah covid-19. Salahsatu media yang bisa digunakan dalam proses pembelajaran jarak jauh yaitu dengan aplikasi google classroom.

Adapun rumusan masalah dalam penelitian ini adalah: (1) Bagaimana Pembelajaran Jarak Jauh (PJJ) menggunakan aplikasi Google Classroom pada mata pelajaran PAI di SMPN 1 Palimanan?, (2) Bagaimana efektivitas belajar bagi siswa mata pelajaran PAI selama pandemi covid-19 di SMPN 1 Palimanan?, (3) Seberapa besar pengaruh penerapan Pembelajaran Jarak Jauh (PJJ) mata pelajaran PAI dengan menggunakan aplikasi Google Classroom terhadap efektifitas belajar bagi siswa di SMPN 1 Palimanan?.

Untuk memperoleh hasil penelitian ini, peneliti menggunakan metode penelitian kuantitatif. Adapun teknik pengumpulan data yang digunakan dalam penelitian ini yaitu: Angket, wawancara, dan dokumentasi. Adapun data yang diperoleh dianalisis dengan melakukan uji variabel dan uji korelasi.

Berdasarkan permasalahan di atas dan setelah dianalisis dapat disimpulkan bahwa: (1) Dalam Pembelajaran Jarak Jauh dengan Aplikasi Google Classroom Pada Mata Pelajaran PAI Selama Pandemi Covid-19 Di SMPN 1 Palimanan termasuk kedalam kategori baik. Karena rekapitulasi hasil perhitungan angket diperoleh hasil sebesar 85,5\%. (2) Efektivitas Belajar Siswa Di SMPN 1 Palimanan masuk dalam kategori baik karena berdasarkan rekapitulasi hasil penghitungan angket mengenai efektivitas belajar diperoleh hasil sebesar $79,7 \%$ yang menunjukkan kategori baik. (3) Terdapat hubungan yang signifikan dan positif antara pembelajaran jarak jauh dengan aplikasi google classroom terhadap efektivitas belajar siswa, karena $r$ bernilai positif. Hal ini dibuktikan dengan perhitungan korelasi dengan menggunakan uji hipotesis korelasi product moment dan didapat nilai koefisien korelasi $r$ sebesar 0,650 yang menunjukkan pada korelasi yang cukup signifikan.

Kata Kunci: efektivitas belajar, google classroom, pembelajaran jarak jauh.

\section{PENDAHULUAN}

Menurut Undang-undang RI Nomor 20 Tahun 2003 tentang Sistem Pendidikan nasional Bab 1 Pasal 1 (1) pendidikan adalah usaha sadar dan terencana untuk mewujudkan suasana belajar dan proses pembelajaran agar peserta didik secara aktif mengembangkan potensi dirinya, masyarakat, bangsa dan negara. Dalam hal ini, tentu saja diperlukan adanya pendidikan professional yakni guru di sekolah-sekolah dasar dan menengah, serta dosen di perguruan-perguruan tinggi sebagaimana yang tersirat dalam Bab XI Pasal 39 (2) UU Sisdiknas tersebut. ${ }^{1}$

\footnotetext{
${ }^{1}$ Muhibbin Syah, Psikologi Pendidikan (Bandung: PT Remaja Rosdakarya ), hlm1 2011.
} 
Dalam Q.S. At-Taubah ayat 122 Allah SWT berfirman:

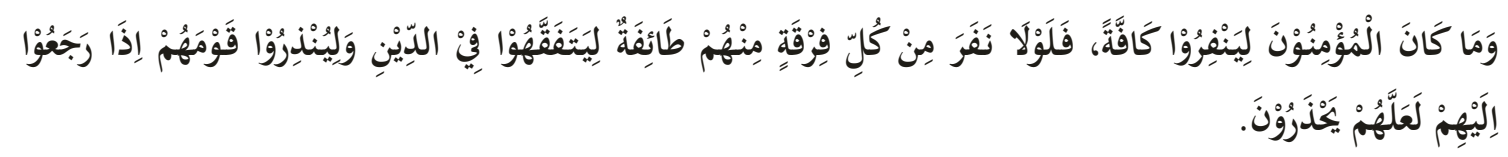

Artinya "tidak pernah wujud (tidak sepantasnya) kaum mukmin seluruhnya keluar untuk berperang, (tetapi) hendaknya ada satu golongan dari mereka yang memperdalam pengetahuan agama dan agar mereka memberi peringatan kepada kaum mereka setelah mereka kembali, agar kaum mereka itu senantiasa berhatihati/waspada".2

Maksud dari ayat tersebut menjelaskan dalam situasi perang dengan kaum kafir Quraish Allah menurunkan wahyu bahwa orang-orang yang sedang thalabul ilmi tidak di anjurkan untuk ikut berjihad. Karena jika ikut berperang bisa saja mereka mati syahid dan ahirnya umat islam tidak memiliki penerus ulama bagi generasi selanjutnya.

Dalam konteks sekarang pada masa pandemi covid-19 ini bukan sebagai hambatan untuk berhenti belajar karena jiwa mereka tidak berhaya di bandingkan dengan orang yang sedang berjihad perang menegakkan Agama Islam. Secara umum, terdapat dua dampak bagi keberlangsungan pendidikan yang disebabkan oleh pandemi covid-19.

Pertama adalah dampak jangka pendek. Dampak ini berupa beban psikologis yang harus ditanggung oleh guru, peserta didik, dan orang tua. Ini menjadi kejutan besar bagi guru karena harus merumuskan ulang perangkat pembelajaran yang ada, baik dari strategi, metode, media, hingga evaluasi yang sesuai dengan pembelajaran daring dan dapat memenuhi tujuan pembelajaran yang telah ditetapkan dengan baik. Bagi orang tua, khususnya yang biasa sibuk dengan pekerjaannya di luar rumah, mendampingi anaknya untuk melakukan proses pembelajaran daring menjadi tambahan beban tersendiri. Demikian juga dengan problem psikologis anak-anak peserta didik yang terbiasa belajar bertatap muka langsung dengan guru-guru dan teman-teman sekelas, namun harus terbiasa belajar mandiri melalui berbagai media yang belum begitu mereka fahami. Bagi guru, sebagai pemegang kunci utama keberhasilan dalam pembelajaran, belajar daringmemiliki dampak yang lebih komplek. Perubahan sistem belajar yang sangat cepat memaksa mereka harus mampu menyiapkan perangkat pembelajaran

\footnotetext{
${ }^{2}$ M. Quraish Shihab, Kaidah Tafsir (Tangerang: Lentera Hati, 2019), hlm 83.
} 
dengan strategi yang sesuai dengan kebutuhan. Guru dituntut untuk meningkatkan kemampuan mereka dalam penguasaan materi, metode, dan media pemmbelajaran agar dapat mencapai tujuan pendidikan yang telah ditentukan.

Kedua adalah dampak jangka panjang. Banyak kelompok masyarakat di Indonesia yang akan terpapar dampak jangka panjang dari Covid-19 ini. Dampak pendidikan dari sisi waktu jangka panjang adalah aspek keadilan dan peningkatan ketidaksetaraan antar kelompok masyarakat dan antar daerah di Indonesia. Ketidaksiapan pelaksana pendidikan daring ini, jika tidak dapat diatasi dengan baik, dapat berakibat pada menurunnya kualitas pendidikan dan lulusan yang dihasilkan.

Dampak dan permasalahan di atas terjadi pada setiap mata pelajaran, khususnya mata pelajaran Pendidikan Agama Islam yang merupakan mata pelajaran utama yang banyak melibatkan pemahaman konsep dan praktik. Muhaimin, berpendapat bahwa pendidikan agama Islam bermakna upaya mendidikkan agama Islam atau ajaran Islam dan nilai-nilainya agar menjadi pandangan dan sikap hidup seseorang. Ini senada dengan pengertian pendidikan Islam, yaitu proses trans-internalisasi pengetahuan dan nilai Islam kepada peserta didik melalui upaya pengajaran, pembiasaan, bimbingan, pengusahaan, pengawasan, pengarahan, dan pengembangan potensi-potensinya, guna mencapai keselarasan dan kesempurnaan hidup di dunia dan akhirat, jasmani dan rohani. Dari aktivitas mendidikkan agama Islam itu bertujuan untuk membantu seseorang atau sekelompok anak didik dalam menanamkan dan/atau menumbuhkembangkan ajaran Islam dan nilai-nilainya untuk dijadikan sebagai pandangan hidupnya. ${ }^{3}$

Berdasarkan realitas di lapangan SMPN 1 Palimanan, Pembelajaran Jarak Jauh (PJJ) yang digunakan khususnya mata pelajaran PAI Sudah cukup maksimal. Namun Penulis menemukan beberapa permasalahan terhadap efektivitas belajar bagi para siswanya, diantaranya masih ada siswa yang tidak memperhatikan materi pembelajaran yang di berikan oleh guru selama PJJ berlangsung. Karena dalam hal ini guru tidak bisa mengawasi pembelajaran secara langsung sehingga siswa sangat mudah untuk tidak mengikuti pembelajaran. Terkadang banyak siswa yang hanya absen saja tanpa memperhatikan materi apa yang sedang mereka pelajari bahkan ada yang menyalah

3 Giyarsi, Strategi Alternatif Dalam Pembelajaran Daring Pendidikan Agama Islam Pada Masa Pandemi Covid 19. Islamic Education Journal Vol 1 Issue 3, 2020. 
gunakan waktu proses kegiatan belajar mengajar untuk bermain game online. Pembelajaran jarak jauh adalah proses belajar mengajar yang dilakukan secara jarak jauh melalui penggunaan berbagai media komunikasi ${ }^{4}$

Mengingat dalam media PJJ sangat beraneka ragam seperti penggunaan Aplikasi WhatsApp Grup, Zoom, Ruang Guru, Google Meet, Edmodo, Google Classroom, dan lain sebagainya. Penulis lebih memilih mengakaji penelitian ini dengan penggunaan Aplikasi Google Classroom. Google Classroom merupakan layanan web yang dikembangkan oleh google. Layanan web ini diperuntukkan bagi sekolah yang bertujuan untuk membuat kegiatan belajar mengajar lebih produktif dan efesien. Ada beberapa fitur yang menunjang pembelajaran dalam Google Classroom, yaitu penugasan, penilaian, komunikasi, arsip pembelajaran, aplikasi sekuler. Dan keamanan pribadi. Layanan Google Classroom dapat dirasakan secara langsung oleh guru maupun siswa. Guru dapat memanfaatkan layanan ini untuk membuat kelas, memberikan tugas, memberikan informasi materi, berkomunikasi, dan berkolaborasi dengan siswa secara teratur. $^{5}$

Secara teori Aplikasi Google Classroom adalah salah satu media pembelajaran yang dapat bermanfaat bagi dunia pendidikan selama situasi pandemi covid-19. Dalam pemanfaatan media aplikasi Google Classroom ini diharapkan mampu mengefektivitaskan pembelajaran khususnya bagi para siswanya. Efektivitas belajar merupakan tingkat pencapaian tujuan pelatihan, pencapaian tujuan tersebut berupa peningkatan pengetahuan dan keterampilan serta pengembangan sikap melalui proses pembelajaran. ${ }^{6}$

Oleh karena itu, penulis ingin mengkaji penelitian yang berjudul "Pengaruh Pembelajaran Jarak Jauh (PJJ) dengan Aplikasi Google Classroom terhadap Efektivitas Belajar bagi Siswa Pada Mata Pelajaran Pendidikan Agama Islam Selama Pandemi Covid - 19 di SMPN 1 Palimanan ”.

Menurut Simonson, Smaldino, Albright, dan Zvacek. Mereka mendefinisikan pembelajaran jarak jauh sebagai pendidikan formal berbasis lembaga, di mana

\footnotetext{
4 Jenri Ambarita Dkk, Pembelajaran Luring (Indramayu: Penerbit Adab, 2020), hlm.2.

5 Hendrik Pandu Paksi dan Ariyanti, Sekolah Dalam Jaringan (Surabaya: Scopindo Media Pustaka, 2020). hlm.3. 2009), hlm. 31

6 Ns. Roymond Simamora, Buku Ajar Pendidikan Dalam Keperawatan (Jakarta: Buku Kedokteran EGC,
} 
kelompok belajarnya terpisah, dan di mana sistem telekomunikasi interaktif digunakan untuk menghubungkan pemelajar, sumber belajar dan instruktur. Definisi ini menunjukkan bahwa pembelajaran jarak jauh memiliki ciri-ciri sebagai berikut:

1. Adanya lembaga formal yang menyenggarakan program pendidikan.

2. Kelompok peserta belajar terpisah dengan pengajar.

3. Digunakan sistem telekomuikasi untuk menghubungkan peserta belajar, sumbersumber belajar, dan pengajar.

Sementara Hillary Perraton (1988), seperti dikutip oleh Schlosser dan Simonson (2006) mendefinisikan pembelajaran jarak jauh secara lebih sederhana lagi, yaitu suatu proses pembelajaran di mana proporsi signifikan pembelajaran dilakukan oleh seseorang yang terpisah jarak dan waktu dengan pemelajar. Menurut Desmond Keegan (1986) yang menyatakan bahwa pembelajaran jarak jauh adalah suatu metode pembelajaran di mana antara peserta belajar dengan pengajarnya terpisah secara fisik. ${ }^{7}$

Google Classroom merupakan layanan web yang dikembangkan oleh google. Layanan web ini diperuntukkan bagi sekolah yang bertujuan untuk membuat kegiatan belajar mengajar lebih produktif dan efesien. Ada beberapa fitur yang menunjang pembelajaran dalam Google Classroom, yaitu penugasan, penilaian, komunikasi, arsip pembelajaran, aplikasi sekuler, dan keamanan pribadi. Layanan Google Classroom dapat dirasakan secara langsung oleh guru maupun siswa. Guru dapat memanfaatkan layanan ini untuk membuat kelas, memberikan tugas, memberikan informasi materi, berkomunikasi, dan berkolaborasi dengan siswa secara teratur.

\section{Kelebihan menggunakan Google Classroom:}

1. Mobile Friendly.

Orang yang baru pertama kali menggunakan Google Classroom pasti tidak mengalami kesulitan saat menggunakannya karena Google sendiri sangat memperhatikan kenyamanan pengguna

2. Pengelolaan tugas yang mudah

Saat guru atau admin memberikan tugas pada siswa, dengan mudahnya siswa dapat melihat pada satu halaman penyedia tugas sehingga tidak dapat merepotkan siswa untuk mencari tugas

7 Dewi Salma Prawiradilaga Dkk, Mozaik Teknologi Pendidikan: E-Learning (Jakarta: Prenadamedia Group, 2016), hlm. 29. 
3. File Google Classroom tersimpan di Google Drive.

Semua file yang dalam bentuk mp4, mp3, doc, pdf, zip, dan lain-lain. Semua file itu masuk secara otomatis ke akun Google Drive

Kelemahan menggunakan Google Classroom:

1. Butuh gawai

Membutuhkan gawai atau PC untuk menyambung internet yang stabil

2. Tersambung dengan internet

Internet harus stabil karena jaringan di Indonesia tidak selalu tersambung dengan baik

3. Tidak dapat berkomunikasi secara verbal.

Guru dengan siswa atau siswa dengan siswa lain tidak dapat berkomunikasi secara verbal, hanya bisa berkomunikasi dengan tulisan. ${ }^{8}$

Konsep efektif berasal dari bahasa Inggris yaitu effective yang berarti berhasil, atau sesuatu yang dilakukan berhasil dengan baik. Efektivitas berasal dari kata efektif yang mengandung pengertian dicapainya keberhasilan dalam mencapai tujuan yang telah ditetapkan. Efektifitas selalu terkait dengan hubungan antara hasil yang diharapkan dengan hasil yang telah dicapai. Menurut Effendy (1989:14) efektifitas didefinisikan sebagai berikut:

"komunikasi yang prosesnya mencapai tujuan yang direncanakan sesuai dengan biaya yang dianggarkan, waktu yang ditetapkan dan jumlah personil yang ditentukan".

Efektifitas menurut pengertian diatas mengartikan bahwa indikator efektivitas dalam arti tercapainya sasaran atau tujuan yang telah ditentukan sebelumnya merupakan sebuah pengukuran di mana suatu target telah tercapai sesuai dengan apa yang telah direncanakan.

Unsur-unsur dari kriteria efektivitas menurut Makmur (2011:7-8) yaitu sebagai berikut:

1. Ketepatan penentuan waktu.

2. Ketepatan perhitungan biaya.

3. Ketepatan dalam pengukuran keberhasilan.

4. Ketepatan dalam menentukan pilihan.

5. Ketepatan berpikir.

${ }^{8}$ Selanjutnya, Hendrik Pandu Paksi dan Ariyanti, Sekolah Dalam Jaringa, hlm. 13-14. 
6. Ketepatan dalam melakukan perintah.

7. Ketepatan dalam melakukan tujuan.

8. Ketepatan sasaran. ${ }^{9}$

Belajar dapat diartikan sebagai komunikasi terencana yang menghasilkan perubahan atas sikap, keterampilan, dan pengetahuan dalam hal sasaran khusus yang berkaitan dengan pola berperilaku yang diperlukan individu untuk mewujudkan secara lengkap tugas ataupun pekerjaan tertentu ( Bramley, 1996). Dengan demikian efektivitas belajar merupakan tingkat pencapaian tujuan pelatihan, pencapaian tujuan tersebut berupa peningkatan pengetahuan dan keterampilan serta pengembangan sikap melalui proses pembelajaran.

Dengan pemahaman di atas, aspek-aspek efektivitas belajar dapat dinyatakan sebagai berikut:

1. Peningkatan pengetahuan.

2. Peningkatan keterampilan.

3. Perubahan sikap.

4. Perubahan perilaku.

5. Kemampuan adaptasi.

6. Peningkatan integrasi.

7. Peningkatan partisipasi.

8. Peningkatan interaksi kebudayaan. ${ }^{10}$

\section{METODE PENELITIAN}

Dalam Penelitian ini penulis menggunakan penelitian kuantitatif, karena data yang diperoleh nantinya berupa angka. Nana Sudjana dan Ibrahim (2007) menjelaskan mengenai pengertian dari metode penelitian korelasional, "studi korelasi mempelajari hubungan dua variabel atau lebih, yakni sejauh mana variasi dalam satu variabel berhubungan dengan variasi dalam variabel lain."

Sumber data dalam penelitian ini adalah data primer. Sumber data adalah segala sesuatu yang dapat memberikan informasi mengenai data.( Sugiyono,2009). Teknik pengumpulan data dalam penelitian yaitu dengan angket,wawancara dan dokumentasi.

9 Muhammad Sawir, Birokrasi Pelayanan Publik Konsep, Teori, Dan Aplikasi (Yogyakarta: DEEPUBLISH, 2020), hlm. 126-127.

${ }^{10}$ Selanjutnya, Ns. Roymond Simamora, Buku Ajar Pendidikan Dalam Keperawatan, hlm. 32. 
Angket/Kuesioner adalah suatu alat pengumpul informasi dengan cara menyampaikan sejumlah pertanyaan tertulis untuk menjawab secara tertulis pula oleh responden (S. Margono 2014). Angket akan disebarkan ke beberapa siswa kelas VIII-C SMPN 1 Palimanan. Untuk alternatif jawaban dalam angket ini yaitu sangat setuju (SS) dengan bobot nilai 4, setuju (S) dengan bobot nilai 3, tidak setuju (TS) dengan bobot nilai 2, dan sangat tidak setuju (STS) dengan bobot nilai 1.

Wawancara merupakan alat pengumpul informasi dengan cara mengajukan pertanyaan secara lisan dan dijawab secara lisan pula melalui kontak langsung dengan tatap muka. (S. Margono,2014) Adapun wawancara dalam penelitian ini adalah wawancara langsung kepada Guru Pendidikan Agama Islam \& Budi Pekerti dan sebagian siswa yang akan di jadikan sampel.

Dokumentasi dari asal kata dokumen yang artinya barang-barang tertulis. (Sukardi, 2003). Beberapa data yang akan didokumentasikan ialah terkait profil sekolah dan penerapan PJJ dengan Aplikasi Google Classroom.

Metode analisis yang menggunakan hasil angket dianalisis dengan menggunakan pendekatan kuantitatif. Dalam pendekatan ini menggunakan rumus deskriptif kuantitatif. Adapun untuk menghitung skala prosentase digunakan rumus sebagai berikut:

$$
P=\frac{F}{N} X 100 \%
$$

Keterangan :

$\mathrm{P} \quad=$ Angka persentase.

$\mathrm{F} \quad=$ Frekuensi yang sedang dicari persentasenya.

$\mathrm{N}=$ Number of cases (jumlahfrekuensi/banyaknya individu).

$100 \%=$ Bilangan tetap. ${ }^{11}$

Pada teknis analisis data selanjutnya penulis menggunakan korelasi product moment untuk mencari koefisien validas alat evaluasi dengan formula sebagai berikut:

$$
r_{x y}=\frac{N \sum x y-\left(\sum x\right)\left(\sum y\right)}{\sqrt{\left\{N \sum x^{2}-\left(\sum x\right)^{2}\left\{N \sum y^{2}-\left(\sum y\right)^{2}\right.\right.}}
$$

11 Anas Sudijono, Pengantar Statistik Pendidikan (Jakarta: PT. Raja Grafindo Persada, 2011), hlm. 43. 
Keterangan :

$\mathrm{r}_{\mathrm{xy}}=$ Koefisien korelasi antara variable $\mathrm{X}$ dan $\mathrm{Y}$.

$\mathrm{N} \quad=$ Jumlah sampel.

$\sum X Y=$ Jumlah hasil perkalian antara skor $\mathrm{X}$ dan skor $\mathrm{Y}$.

$\sum X \quad=$ Jumlah skor variabel $\mathrm{X}$.

$\sum Y=$ Jumlah skor variabel $\mathrm{Y}$.

$\sum x^{2}=$ Jumlah kuadrat skor variabel $\mathrm{X}$.

$\sum y^{2}=$ Jumlah kuadrat skor variabel Y.$^{12}$

Selanjutnya untuk menyatakan besar kecilnya sumbangan variable $X$ terhadap variable Y dapat ditentukan dengan rumus koefisien determinasi sebagai berikut :

$K D=r^{2} \times 100 \%$

Keterangan:

KD : Koefisien Determinasi.

$r 2$ : koefisien yang dikuadratkan.

$100 \%$ : persentase. (Subana dkk, 2000).

Selanjutnya untuk mengetahui taraf signifikan dari variabel $\mathrm{x}$ terhadap variabel y langkah selanjutnya adalah mengkonsultasikan atau membandingkan antara nilai dalam koefisien korelasi dengan nilai $r$ tabel pada taraf signifikan $1 \%$ dan $5 \%$ dengan terlebih dahulu mencari nilai derajat bebasnya $(\mathrm{db})$ dengan rumus sebagai berikut:

$\mathrm{Db}=\mathrm{N}-\mathrm{nr}$

Keterangan:

$\mathrm{Db}=$ derajat bebas.

$\mathrm{N} \quad=$ jumlah responden.

$\mathrm{nr} \quad=$ jumlah variabel.

Dengan memeriksa nilai " $\mathrm{r}$ " product moment pada taraf signifikan $1 \%$ dan $5 \%$, jika $\mathrm{r}$ tabel lebih kecil dari rxymaka hipotesis nol (Ho) di tolak dan hipotesis alternatif (ha) disetuji atau diterima.

\footnotetext{
12 Anas Sudijono, Pengantar Statistik Pendidikan, hlm. 206.
} 


\section{HASIL PENELITIAN DAN PEMBAHASAN}

1. Pembelajaran Jarak Jauh Google Classroom pada Mata Pelajaran Pendidikan Agama Islam Selama Pandemi Covid-19 di SMPN 1 Palimanan.

\section{Tabel 1}

Rekapitulasi Nilai dan kategori Data per item Angket Pembelajaran Jarak Jauh (PJJ) dengan Aplikasi Google Classroom pada Mata Pelajaran PAI Selama Pandemi Covid-19 di SMPN 1 Palimanan.

\begin{tabular}{c|l|l|l} 
No. & Item Angket & Nilai & Kategori \\
\hline 1 & $\begin{array}{l}\text { Penggunaan google classroom } \\
\text { bisa dibawa di tas }\end{array}$ & $90 \%$ & Baik \\
\hline 2 & $\begin{array}{l}\text { Penggunaan google classroom } \\
\text { bisa dibawa di kantong saku }\end{array}$ & $92,5 \%$ & Baik \\
\hline 3 & $\begin{array}{l}\text { Penggunaan google classroom } \\
\text { bisa sambil di rumah }\end{array}$ & $92,5 \%$ & Baik \\
\hline 4 & $\begin{array}{l}\text { Penggunaan google classroom } \\
\text { bisa sambil di sekolah }\end{array}$ & $80 \%$ & Baik \\
\hline 5 & $\begin{array}{l}\text { Penggunaan google classroom } \\
\text { bisa sambil di jalan }\end{array}$ & $80 \%$ & Baik \\
\hline 6 & $\begin{array}{l}\text { Guru dapat memposting tugas } \\
\text { dengan mudah }\end{array}$ & $87,5 \%$ & Baik \\
\hline 7 & $\begin{array}{l}\text { Guru dapat melihat hasil tugas } \\
\text { siswa dengan mudah }\end{array}$ & $90 \%$ & Baik \\
\hline 8 & $\begin{array}{l}\text { Guru dapat menilai tugas siswa } \\
\text { dengan mudah }\end{array}$ & $87,5 \%$ & Baik \\
\hline 9 & $\begin{array}{l}\text { Siswa dapat mengumpulkan } \\
\text { tugas dengan mudah }\end{array}$ & $85 \%$ & Baik \\
\hline 10 & $\begin{array}{l}\text { Siswa dapat melihat hasil tugas } \\
\text { dengan mudah }\end{array}$ & $80 \%$ & Baik \\
\hline 11 & $\begin{array}{l}\text { Aplikasi google classroom lebih } \\
\text { ramah lingkungan karena dapat } \\
\text { meminimalisir penggunaan } \\
\text { kertas materi pembelajaran }\end{array}$ & $82,5 \%$ & Baik \\
\hline 12 & $\begin{array}{l}\text { Siswa dapat melihat materi yang } \\
\text { telah lewat }\end{array}$ & $80 \%$ & Baik \\
\hline 13 & $\begin{array}{l}\text { Guru tidak perlu khawatir akan } \\
\text { hilangnya file pembelajaran }\end{array}$ & $85 \%$ & Baik \\
\hline 14 & $\begin{array}{l}\text { Siswa dapat melihat dan } \\
\text { mengulang materi }\end{array}$ & $82,5 \%$ & Baik \\
\hline 15 & $\begin{array}{l}\text { Semua fie tersimpan di google } \\
\text { drive }\end{array}$ & $85 \%$ & Baik \\
\hline 16 & $\begin{array}{l}\text { Penggunaan google classroom } \\
\text { harus dengan data internet }\end{array}$ & $87,5 \%$ & Baik \\
\hline 17 & $\begin{array}{l}\text { Penggunaan google classroom } \\
\text { bisa melalui wifi }\end{array}$ & $87,5 \%$ & Baik \\
\hline 18 Penggunaan google classroom & $90 \%$ & Baik \\
\hline
\end{tabular}




\begin{tabular}{|c|c|c|c|}
\hline No. & Item Angket & Nilai & Kategori \\
\hline & bisa melalui hotspot seluler & & \\
\hline 19 & $\begin{array}{l}\text { Kartu telkomsel cocok dalam } \\
\text { penggunaan google classroom }\end{array}$ & $85 \%$ & Baik \\
\hline 20 & $\begin{array}{l}\text { Kartu axiz cocok dalam } \\
\text { penggunaan google classroom }\end{array}$ & $90 \%$ & Baik \\
\hline 21 & $\begin{array}{l}\text { Kartu } 3 \text { cocok dalam } \\
\text { penggunaan google classroom }\end{array}$ & $87,5 \%$ & Baik \\
\hline 22 & $\begin{array}{l}\text { Kartu indosat cocok dalam } \\
\text { penggunaan google classroom }\end{array}$ & $87,5 \%$ & Baik \\
\hline 23 & Berkomunikasi satu arah & $85 \%$ & Baik \\
\hline 24 & $\begin{array}{l}\text { Komunikasi bisa dalam kolom } \\
\text { komentar }\end{array}$ & $87,5 \%$ & Baik \\
\hline 25 & Berkomunikasi dengan tulisan & $90 \%$ & Baik \\
\hline
\end{tabular}

Tabel 2

Jumlah Item Angket Variabel X.

\begin{tabular}{|c|c|}
\hline No. Res. & Jumlah \\
\hline 1 & 99 \\
\hline 2 & 78 \\
\hline 3 & 81 \\
\hline 4 & 82 \\
\hline 5 & 68 \\
\hline 6 & 91 \\
\hline 7 & 67 \\
\hline 8 & 93 \\
\hline 9 & 100 \\
\hline 10 & 83 \\
\hline 11 & 89 \\
\hline 12 & 74 \\
\hline 13 & 78 \\
\hline 14 & 87 \\
\hline 15 & 84 \\
\hline 16 & 76 \\
\hline 17 & 96 \\
\hline 18 & 77 \\
\hline 19 & 92 \\
\hline 20 & 95 \\
\hline 21 & 84 \\
\hline 22 & 76 \\
\hline 23 & 72 \\
\hline 24 & 73 \\
\hline 25 & 95 \\
\hline 26 & 100 \\
\hline 27 & 81 \\
\hline 28 & 100 \\
\hline 29 & 97 \\
\hline \multirow[t]{2}{*}{30} & 97 \\
\hline & 2565 \\
\hline
\end{tabular}

Selanjutnya dari hasil angket di atas, dicari seberapa besar prosentase prosentase pembelajaran jarak jauh dengan aplikasi google classroom (skor Variabel $\mathrm{X}$ ) dengan menggunakan rumus sebagai berikut: 


$$
\frac{S O}{S T} \times 100 \%
$$

Keterangan:

SO $($ Skor Observasi) = Jumlah skor variabel X.

$\mathrm{ST}$ (Skor Total) = N $\mathrm{x}$ jumlah pertanyaan $\mathrm{x}$ jumlah option.

Diketahui:

$$
\begin{aligned}
& \text { SO }=2565 \\
& \text { ST }=30 \times 25 \times 4=3000 \\
& =\frac{2565}{3000} \times 100 \% \\
& =85,5 \%
\end{aligned}
$$

Berdasarkan rekapitulasi hasil penghitungan angket di atas mengenai prosentase pembelajaran jarak jauh dengan aplikasi google classroom diperoleh hasil sebesar 85,5\%, ini artinya berada pada rentang prosentase $76 \%-100 \%$ yang menunjukan baik.

2. Efektivitas Belajar Siswa pada Mata Pelajaran PAI Selama Pandemi Covid-19 di SMPN 1 Palimanan 


\section{Tabel 3}

Rekapitulasi Nilai dan kategori Data per item Angket Efektivitas Belajar Siswa pada Mata Pelajaran PAI Selama Pandemi Covid-19 di SMPN 1 Palimanan

\begin{tabular}{|c|c|c|c|}
\hline No. & Item Angket & Nilai & Kategori \\
\hline 1 & $\begin{array}{l}\text { pembelajaran jarak jauh memudahkan } \\
\text { saya untuk bertanya }\end{array}$ & $80 \%$ & Baik \\
\hline 2 & $\begin{array}{l}\text { pembelajaran jarak jauh membuat saya } \\
\text { aktif berargumen }\end{array}$ & $74 \%$ & Cukup \\
\hline 3 & $\begin{array}{l}\text { guru memberikan kebebasan pada } \\
\text { siswa untuk aktif dalam pembelajaran }\end{array}$ & $81,5 \%$ & Baik \\
\hline 4 & $\begin{array}{l}\text { guru menerima pertanyaan dari siswa } \\
\text { dalam pembelajaran }\end{array}$ & $75,75 \%$ & Cukup \\
\hline 5 & guru menjawab pertanyaan dari siswa & $77,5 \%$ & Baik \\
\hline 6 & guru responsif kepada siswa & $82,5 \%$ & Baik \\
\hline 7 & $\begin{array}{c}\text { bersemangat untuk mengikuti } \\
\text { pembelajaran }\end{array}$ & $83,25 \%$ & Baik \\
\hline 8 & $\begin{array}{l}\text { tidak bermain game online saat } \\
\text { pembelajaran }\end{array}$ & $80,75 \%$ & Baik \\
\hline 9 & hadir dan mengikuti pembelajaran & $80,75 \%$ & Baik \\
\hline 10 & $\begin{array}{l}\text { guru mampu membuat siswanya untuk } \\
\text { antusias dalam pembelajaran }\end{array}$ & $75 \%$ & Cukup \\
\hline 11 & guru menguasai materi pembelajaran & $77,5 \%$ & Baik \\
\hline 12 & $\begin{array}{c}\text { Guru mampu mencairkan suasana } \\
\text { disela pembelajaran }\end{array}$ & $73,25 \%$ & Cukup \\
\hline 13 & Guru bersikap ramah terhadap siswa & $75,75 \%$ & Cukup \\
\hline 14 & $\begin{array}{c}\text { Selama proses pembelajaran guru dapat } \\
\text { menumbuhkan sikap positif kepada } \\
\text { siswanya }\end{array}$ & $73,25 \%$ & Cukup \\
\hline 15 & $\begin{array}{c}\text { Guru memberikan 92able9292 kepada } \\
\text { siswa agar tetap semangat mengikuti } \\
\text { pembelajaran }\end{array}$ & $77,5 \%$ & Baik \\
\hline 16 & $\begin{array}{l}\text { Guru yang menyenangkan pada saat } \\
\text { pembelajaran membuat saya senang }\end{array}$ & $82,5 \%$ & Baik \\
\hline 17 & $\begin{array}{l}\text { semakin ingin mempelajari materi } \\
\text { pembelajaran menjadi menyenangkan } \\
\text { karea gurunya baik }\end{array}$ & $80 \%$ & Baik \\
\hline 18 & materi pembelajaran mudah dipahami & $81,5 \%$ & Baik \\
\hline 19 & $\begin{array}{l}\text { guru telaten dengan perkembangan } \\
\text { siswa dalam pembelajaran }\end{array}$ & $80 \%$ & Baik \\
\hline 20 & Guru mempunyai indikator penilaian & $83,25 \%$ & Baik \\
\hline 21 & $\begin{array}{l}\text { materi pembelajaran membuat saya } \\
\text { mudah }\end{array}$ & $80,75 \%$ & Baik \\
\hline 22 & $\begin{array}{l}\text { materi pembelajaran membuat saya } \\
\text { senang }\end{array}$ & $82,5 \%$ & Baik \\
\hline 23 & Tugas diselesaikan tepat waktu & $80,75 \%$ & Baik \\
\hline 24 & $\begin{array}{l}\text { Nilai yang didapatkan sesuai atau } \\
\text { melebihi KKM }\end{array}$ & $87,5 \%$ & Baik \\
\hline 25 & Pembelajaran menjadi lebih efektif & $85,75 \%$ & Baik \\
\hline
\end{tabular}


Tabel 4

Jumlah Item Angket Variabel y. Menunjukkan. Jumlah Res.

\begin{tabular}{c|c}
\hline 1 & 88 \\
\hline 2 & 72 \\
\hline 3 & 76 \\
\hline 4 & 76 \\
\hline 5 & 72 \\
\hline
\end{tabular}

\begin{tabular}{c|c}
\hline 6 & 84 \\
\hline 7 & 68 \\
\hline 8 & 80 \\
\hline 9 & 76 \\
\hline 10 & 76 \\
\hline 11 & 80
\end{tabular}

\begin{tabular}{c|c}
\hline 11 & 80 \\
\hline 12 & 80 \\
\hline 13 & 80 \\
\hline 14 & 80 \\
\hline 15 & 76
\end{tabular}

\begin{tabular}{c|c}
15 & 76 \\
\hline 16 & 76 \\
\hline 17 & 88 \\
\hline 18 & 76 \\
\hline 19 & 84 \\
\hline
\end{tabular}

\begin{tabular}{c|c}
\hline 20 & 95 \\
\hline 21 & 84 \\
\hline 22 & 76 \\
\hline 23 & 76 \\
\hline 24 & 76 \\
\hline 25 & 92 \\
\hline 26 & 80 \\
\hline 27 & 80 \\
\hline 28 & 96 \\
\hline 29 & 84 \\
\hline 30 & 88 \\
\hline & 2392
\end{tabular}

Selanjutnya dari hasil angket di atas, dicari seberapa besar prosentase efektivitas belajar (skor Variabel Y) dengan menggunakan rumus sebagai berikut:

$$
\frac{S O}{S T} \times 100 \%
$$

Keterangan:

SO $($ Skor Observasi) = Jumlah skor 93able9393e X. 
ST $($ Skor Total $) \quad=\mathrm{N} \times$ jumlah pertanyaan $\mathrm{x}$ jumlah option .

Diketahui:

$$
\begin{aligned}
& \text { SO }=2392 \\
& \text { ST }=30 \times 25 \times 4=3000 \\
& =\frac{2392}{3000} \times 100 \% \\
& =79,7 \%
\end{aligned}
$$

Berdasarkan rekapitulasi hasil penghitungan angket di atas mengenai efektivitas belajar diperoleh hasil sebesar 79,7\%, ini artinya berada pada rentang prosentase $76 \%-100 \%$ yang menunjukkan baik.

3. Pengaruh Pembelajaran Jarak Jauh (PJJ) dengan Aplikasi Google Classroom Terhadap Efektivitas Belajar bagi Siswa pada Mata Pelajaran Pendidikan Agama Islam Selama Pandemi Covid-19 di SMPN 1 Palimanan.

Untuk mengetahui ada tidaknya pengaruh dari pembelajaran jarak jauh dengan aplikasi google classroom (x) terhadap efektivitas belajar sebagai variabel (y), maka penulis sajikan kedua data variabel yang diperoleh dari hasil angket terhadap 30 siswa sebagai responden. Kemudian akan dikorelasikan dengan menggunakan rumus korelasi product moment.

Tabel 5

Korelasi produk moment SPSS

Correlations

\begin{tabular}{|cc|c|c|}
\hline & & PJJ GCR & $\begin{array}{c}\text { Efektivitas } \\
\text { Belajar }\end{array}$ \\
\hline PJJ GCR & Pearson Correlation & 1 &, $650^{* *}$ \\
& Sig. (2-tailed) & &, 000 \\
Efektivitas & Pearson Correlation &, $650^{* *}$ & 30 \\
Belajar & Sig. (2-tailed) &, 000 & 1 \\
& $\mathrm{~N}$ & 30 & 30 \\
\hline
\end{tabular}

**. Correlation is significant at the 0.01 level (2-tailed). 
Berdasarkan hasil perhitungan di atas, diperoleh nilai koefisien antara penerapan Pembelajaran Jarak Jauh Dengan Aplikasi Googl Classroom terhadap Efektivitas Belajar Bagi Siswa Pada Mata Pelajaran Pendidikan Agama Islam Selama Pandemi Covid-19 Di SMPN 1 Palimanan sebesar $r_{x y}=0,650$. Indeks tersebut menunjukkan angka positif dan terletak pada interval 0,40 0,70. Selanjutnya berdasarkan kriteria tersebut makna koefisien korelasinya termasuk dalam kategori korelasi yang sedang atau cukup

selanjutnya untuk mengetahui prosentase efektivitas antara variabel $\mathrm{x}$ (penerapan pembelajaran jarak jauh dengan aplikasi google classroom terhadap variabel y (efektivitas belajar) bagi siswa pada mata pelajaran pendidikan agama islam selama pandemi covid-19 di SMPN 1 Palimanan, maka digunakan rumus koefisien determinasi, sebagai berikut:

$$
\begin{aligned}
\mathrm{KD} & =\left(r_{x y}\right)^{2} \times 100 \% \\
& =(0,650)^{2} \times 100 \% \\
& =0,4225 \times 100 \% \\
& =42,25 \%
\end{aligned}
$$

Dari hasil perhitungan tersebut dapat disimpulkan bahwa seberapa Efektivitas Belajar ditentukan oleh penerapan Pembelajaran Jarak Jauh dengan Aplikasi Google Classroom sebesar $42.25 \%$. Maka $57.75 \%$ lagi ditentukan oleh 95able95 lain yang tidak diteliti dalam penelitian ini, misalnya melalui penerapan aplikasi Whats App, Zoom, Google Meet, Edmodo dan lain sebagainya.

Untuk mengetahui $r_{x y}$ signifikan atau tidak dapat dilakukan dengan mengkonsultasikanya pada 95able distribusi "t" dengan terlebih dahulu mencari nilai $t_{\text {hitung }}$ dengan menggunakan rumus sebagai berikut:

$$
\begin{aligned}
t_{\text {hitung }}= & \frac{r \sqrt{n-2}}{\sqrt{1-r^{2}}} \\
& =\frac{0,650 \sqrt{30-2}}{\sqrt{1-(0,650)^{2}}} \\
& =\frac{0,650 \sqrt{28}}{\sqrt{1-0,4225}} \\
& =\frac{0,650 \cdot(5,291)}{\sqrt{0,5775}} \\
& =\frac{3,43915}{0,760}
\end{aligned}
$$




$$
=4,525
$$

Mencari $\mathrm{t}_{\text {tabel }} a=0,05$ atau $5 \%$

$$
\begin{aligned}
\mathrm{df} & =(\mathrm{n}-2)=30-2=28 \\
28 & =1,701
\end{aligned}
$$

Maka, $t_{\text {hitung }}=4,525>t_{\text {tabel }}=1,701$

Kaidah pengujian :

1) Jika t hitung $\geq t$ table berarti signifikan

2) Jika t hitung $\leq \mathrm{t}$ 96able berarti tidak signifikan

Berdasarkan perhitungan di atas, dapat disimpulkan bahwa perolehan nilai " $\mathrm{t}$ " tersebut dengan $\mathrm{df}=30-2=28$ adalah 1,701 dalam table " $\mathrm{t}$ " pada taraf signifikansi 0,05 adalah 1,701 sedangkan nilai $t_{\text {hitung }}=4,525$. Oleh karena itu, $t_{\text {hitung }}>t_{\text {tabel }}$ yaitu $4,525>1,701$. Artinya perolehan nilai $t_{\text {hitung }}>t_{\text {tabel }}$ maka Ha diterima dan Ho ditolak. Dengan kata lain berdasarkan kaidah di atas artinya hipotesis yang menyatakan bahwa terdapat pengaruh pembelajaran jarak jauh dengan aplikasi google classroom terhadap efektivitas belajar bagi siswa pada mata pelajaran pendidikan agama islam selama pandemi covid-19 di SMPN 1 Palimanan adalah signifikan.

\section{SIMPULAN}

Berdasarkan hasil analisis data yang telah diperoleh dari hasil pengujian data di atas. Maka dapat ditarik kesimpulan sebagai berikut :

1. Dari hasil penelitian menunjukkan bahwa Pembelajaran Jarak Jauh dengan Aplikasi Google Classroom Pada Mata Pelajaran PAI Selama Pandemi Covid-19 Di SMPN 1 Palimanan termasuk kedalam kategori baik. Dengan demikian berdasarkan rekapitulasi hasil perhitungan angket mengenai Pembelajaran Jarak Jauh dengan Aplikasi Google Classroom diperoleh hasil sebesar $85,5 \%$, hasil tersebut berada pada rentang prosentase $76-100 \%$ yang menunjukkan baik.

2. Hasil penelitian Efektivitas Belajar Siswa Di SMPN 1 Palimanan masuk dalam kategori baik karena berdasarkan rekapitulasi hasil penghitungan 
angket di bab iv mengenai efektivitas belajar diperoleh hasil sebesar 79,7\%, ini artinya berada pada rentang prosentase $76 \%$ - 100\% yang menunjukan baik.

3. Pengaruh Pembelajaran Jarak Jauh dengan Aplikasi Google Classroom Terhadap Efektivitas Belajar Siswa Classroom pada Mata Pelajaran PAI Selama Pandemi Covid-19 Di SMPN 1 Palimanan menunjukkan nilai korelasi yang mencapai $\mathrm{rxy}=0,650$ yang menunjukkan pada korelasi yang cukup, karena berada pada interval. 0,40 - 0,70. Hal tersebut menunjukkan hubungan yang cukup signifikan antara pembelajaran jarak jauh dengan aplikasi google classroom (Variabel X) terhadap efektivitas belajar siswa (Variabel Y) pada mata pelajaran PAI di SMPN 1 Palimanan. Adapun koefisien determinasi penggunaan google classroom terhadap efeketivitas belajar adalah sebesar $42,25 \%$ dan sisanya $57,75 \%$ lagi ditentukan oleh faktor lain yang tidak diteliti dalampenelitian ini, misalnya melalui penerapan aplikasi WhatsApp, Zoom, Google Meet, Edmodo dan lain sebagainya. Adapun signifikansi efektivitasnya dapat disimpulkan sebagai signifikansi karena nilai " $\mathrm{t}$ " dengan $\mathrm{df}=30-2=28$ adalah 1,701 dalam tabel " $t$ " pada taraf signifikansi 0,05 adalah 1,701 artinya perolehan nilai $t_{\text {hitung }} \geq t_{\text {tabel }}$ maka $\mathrm{H}_{\mathrm{a}}$ diterima dan $\mathrm{H}_{0}$ ditolak. Dengan kata lain berdasarkan kaidah di atas artinya hipotesis yang menyatakan bahwa Terdapat Pengaruh Pembelajaran Jarak Jauh Dengan Aplikasi Google Classroom Terhadap Efektivitas Belajar Bagi Siswa Pada Mata Pelajaran Pendidikan Agama Islam Selama Pandemi Covid-19 Di SMPN 1 Palimanan adalah signifikan.

\section{DAFTAR PUSTAKA}

Ambarita, Jenri Dkk. Pembelajaran Luring. Indramayu: Penerbit Adab. 2020.

Arikunto, S. Prosedur Penelitian Suatu Pendekatan Praktek. Jakarta: Rineka Cipta. 2002.

Giyarsi. Strategi Alternatif Dalam Pembelajaran Daring Pendidikan Agama Islam Pada Masa Pandemi Covid 19. Islamic Education Journal Vol 1 Issue 3. (2020). 
Paksi, Hendrik Pandu. Sekolah Dalam Jaringan. Surabaya: Scopindo Media Pustaka. 2020.

Prawiradilaga, Dewi Salma Dkk. Mozaik Teknologi Pendidikan: E-Learning. Jakarta: Prenadamedia Group. 2016.

Sawir, Muhammad. Birokrasi Pelayanan Publik Konsep, Teori, Dan Aplikasi. Yogyakarta: DEEPUBLISH. 2020.

Shihab, M. Quraish. Kaidah Tafsir. Tangerang: Lentera Hati. 2019.

Simamora, Ns. Roymond. Buku Ajar Pendidikan Dalam Keperawatan. Jakarta: Buku Kedokteran EGC. 2009.

Sudjana, Nana dan Ibrahim. Penelitian dan Penilaian Pendidikan. Bandung: Sinar Baru. 2007.

Sudijono, Anas. Pengantar Statistik Pendidikan. Jakarta: PT. Raja Grafindo Persada. 2011.

Sugiyono. Metode Penelitian Kuantitatif, Kualitatif, Dan R\&D. Bandung: Alfabeta. 2018.

Syah, Muhibbin. 2011. Psikologi Pendidikan. Bandung: PT Remaja Rosdakarya. 